Printed in Great Britain

\title{
Electron Microscope Observations on the Surface Structures of Streptomyces violaceoruber
}

\author{
By D. A. HOPWOOD \\ Botany School, University of Cambridge \\ AND AUDREY M. GLAUERT \\ Strangeways Research Laboratory, Cambridge
}

(Received 30 March 1961)

SUMMARY

The surface structures of Streptomyces violaceoruber were studied by electron microscopy of intact organisms, carbon replicas and preparations of walls from disrupted organisms. A surface layer with a fibrillar structure was observed on the aerial hyphae and spores in all three types of preparation. The fate of this layer during spore formation and germination was studied; it is a loose covering which breaks when the spores separate and when the germ tubes emerge, and it is easily lost when the organisms are disrupted. No organized surface structures were observed on the underlying hyphal or spore walls.

\section{INTRODUCTION}

We have recently studied the fine structure of the actinomycete Streptomyces violaceoruber ( $S$. coelicolor) in electron micrographs of thin sections (Glauert \& Hopwood, 1959, 1960, 1961; Hopwood \& Glauert, 1960). Sectioning reveals few details of the surface structure of a specimen; in a transverse section only a small fraction of the surface is seen, while oblique sections are often difficult to interpret. Observations on thin sections have therefore been supplemented with an investigation of intact organisms, carbon replicas, and fragments of walls in preparations of disrupted organisms. The results of this investigation are described here.

\section{METHODS}

Organism. Streptomyces violaceoruber (S. coelicolor) strain A3 (2) (Hopwood, 1960). Mounting specimens on electron microscope grids. Spores and fragments of aerial hyphae were mounted on Formvar-coated grids by gently touching the Formvar film on the surface of a 4- to 6-day colony growing on complete agar medium (Hopwood, 1960). Preparations of germinating spores and hyphae of the substrate mycelium were obtained by the method developed for mycobacteria by Brieger, Cosslett \& Glauert (1954). A thin layer of cottonwool soaked in liquid medium was placed in a Petri dish and covered with a disk of filter paper. Grids which had been inoculated with spores as described above were placed on the filter paper with the Formvar film uppermost, and the dish incubated at $30^{\circ}$. After incubation the grids were removed, floated on distilled water to remove traces of growth medium, and 
placed on clean filter paper to dry. Care was taken not to allow any medium or water to get on to the upper surfaces of the grids and so contaminate them.

Organisms that were dried in air were found to be seriously distorted (Pl. 1, fig. 3; Pl. 3, fig. 12) because they collapsed on to the support film; therefore the preparations were freeze-dried. A simple freeze-drying apparatus designed by Dr M. J. P. Canny was used. Grids carrying the specimens were placed one at a time on a copper disk of 1 in. diam. (a halfpenny) which had been previously cooled to about $-195^{\circ}$ by immersion in liquid nitrogen. After a few seconds the grids were rapidly transferred to a Quickfit test tube of internal diameter $34 \mathrm{~mm}$., which was kept at a temperature of about $-80^{\circ}$ by immersion in a mixture of acetone and solid carbon dioxide in a vacuum flask. When the grids had all been transferred, the test tube was connected by a vacuum joint to a wide L-shaped tube. The horizontal limb of the tube contained a small boat filled with dry phosphorus pentoxide and its open end was closed with a Quickfit stopper of $34 \mathrm{~mm}$. diameter. A side arm from the drying tube was connected to an Edwards two-stage rotary pump, Model 2S20 B, which decreased the pressure in the freeze-drying apparatus to about $0.05 \mathrm{~mm}$. $\mathrm{Hg}$. The specimens were dried for about $16 \mathrm{hr}$.

Some preparations of intact organisms were shadowed with gold-palladium $(60: 40)$ before examination in the electron microscope.

Carbon replicas. Replicas were made by the method described by Bradley \& Williams (1957) for the examination of the spores of bacilli. Freeze-dried specimens were transferred directly from the freeze-drying apparatus to the vacuum chamber for carbon evaporation. The carbon replicas were not metal-shadowed because it was found that granulation of the shadowing metal obscured the finer details of the surface structures.

Negative staining. A suspension of spores and small fragments of aerial mycelium was prepared as described by Glauert \& Hopwood (1960). The organisms were disrupted by shaking the suspension in a Mickle tissue disintegrator (Mickle, 1948). with an equal volume of grade 12 ballotini for $5 \mathrm{~min}$. Unbroken organisms were

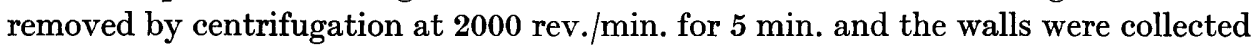
by centrifugation at $10,000 \mathrm{rev} . / \mathrm{min}$. for $20 \mathrm{~min}$. The pellet was thoroughly dispersed in a small volume of water, and the resulting suspension was mixed with an equal volume of a $2 \%(\mathrm{w} / \mathrm{v})$ solution of phosphotungstic acid adjusted to $\mathrm{pH} 7 \cdot 4$. with N-KOH (Brenner \& Horne, 1959). Minute drops of the mixture were placed with a fine pipette on electron microscope grids coated with collodion films stabilized with a layer of carbon and allowed to dry.

Electron microscopy. Observations were made with a Siemens Elmiskop I operating at 60 or $80 \mathrm{kV}$ with a $50 \mu$ objective aperture, and photographs were taken at instrumental magnifications of $\times \mathbf{5 0 0 0}$ to $\mathbf{2 0 , 0 0 0}$ on Ilford Special Contrasty Lantern Plates.

\section{RESULTS}

\section{Intact organisms}

Information obtained from the study of intact hyphae and spores of Streptomyces violaceoruber in the electron microscope adds little to the knowledge gained by phase-contrast microscopy (Hopwood, 1960). The resolution of structures in the electron micrographs is low because the organisms are too thick to be penetrated 
appreciably by the electron beam. The spores either appear uniformly opaque (P1. 1, figs. 1, 2), or else, in air-dried preparations (Pl. 1, fig. 3), show light areas where the protoplasm has shrunk irregularly during drying; no significant internal structure is visible. The spines that are present on the spores of some other strains of Streptomyces (Flaig, Beutelspacher, Küster \& Segler-Holzweissig, 1952; Baldacci $\&$ Grein, 1955) are not found in $S$. violaceoruber. Some spores have an irregular outline (Pl. 1, fig. 1), while others are smooth (Pl. 1, fig. 2); the irregular contour appears to be caused by a loose superficial layer which readily comes away, to leave the spores smooth-surfaced. Occasionally some details of the structure of this layer can be seen when it is partially separated from the spores (Pl. 1, fig. 4). In shadowed preparations it appears to consist of fibrils which are straight or slightly curved, often paired, and intersect at various angles to form a 'basket-work' pattern.

\section{Carbon replicas}

The walls of the substrate hyphae (PI. 1, fig. 5) show no organized structure in carbon replicas; the surfaces have merely the same fine stippling, with light and dark circles, that is visible on the background. The aerial hyphae have a quite different appearance and are covered with a pattern of intersecting fibrils (PI. 1, fig. 6), which are 5-10 $\mathrm{m} \mu$ in diameter and $100 \mathrm{~m} \mu$ or more long. Although often in pairs, the fibrils also occur singly, and sometimes a number of them radiate from one point; some appear beaded. Thus the aerial hyphae are covered with a fibrous layer which in thin sections (Glauert \& Hopwood, 1961) can be seen to form a loose covering outside the wall of the hypha proper. The fibrous layer remains intact while the spores are forming (Pl. 2, figs. 7, 8), but as they begin to separate from one another, the outer layer of the wall of the parent hypha ruptures between adjacent spores (Glauert \& Hopwood, 1961) and with it the fibrous layer, so that the underlying and apparently structureless spore wall is revealed (Pl. 2, fig. 9, SW; Pl. 3, fig. 11, SW). Each spore in a chain is surrounded by a sac consisting of the outer component of the parent hyphal wall, overlaid by the fibrous layer. Sometimes this sac is loose-fitting (Pl. 2, fig. 8) and sometimes it closely invests the mature spore (Pl. 2, fig. 10). As the spore germinates, the germ tubes, with apparently structureless walls, emerge through the sac (Pl. 3, fig. 13; Pl. 4, fig. 14).

\section{Negative staining}

Observations on fragments of cell walls in preparations of disrupted organisms examined by the negative staining technique of Brenner \& Horne (1959) confirmed the results obtained from studies of carbon replicas. The surfaces of the aerial hyphae and the spores showed no defined structural pattern except in the regions where fragments of the fibrous layer were still present (Pl. 4, fig. 15). The fragility of the superficial fibrous layer is evident in these preparations; it is usually lost during the disruption of the organisms in the Mickle tissue disintegrator.

\section{DISCUSSION}

The negative staining technique of Brenner \& Horne (1959) did not demonstrate fine structure within the walls of Streptomyces violaceoruber, although the technique is capable of very high resolution, and has revealed an ordered array of minute subunits in the walls of certain large cocci (Drs M. J. Thornley and R. W. Horne, 
personal communication; Professor R. G. E. Murray, personal communication). Spherical subunits have been seen in electron micrographs of the walls of some bacteria (Houwink, 1953, 1956; Labaw \& Mosley, 1954, Salton \& Williams, 1954; Van Iterson, 1954) even without the use of the negative staining technique. Thus it seems that the surfaces of the walls of $S$. violaceoruber are smooth, and that the subunits seen in electron micrographs of thin sections (Glauert \& Hopwood, 1961) do not give rise to irregularities on the surface. It remains to be seen whether they can be made visible in unsectioned preparations by controlled degradation of the wall.

In electron micrographs of intact organisms (Pl. 1, figs. 1, 2), the spores appear smooth or slightly irregular, and occasionally it can be seen that the irregularity is due to a detachable fibrous layer which covers the smooth spore wall. Vernon (1955) described the fine structure of a similar layer in a metal-shadowed preparation of an aerial hypha of an unnamed streptomycete, and stated that it consisted of narrow pointed plates lying side by side in groups at various angles, but he did not recognize the distinction between this fragile superficial layer and the structureless wall of the hypha underneath. The fibrous layer can be seen in electron micrographs of thin sections (Glauert \& Hopwood, 1961) as a coat covering the double-layered wall of the aerial hyphae. During sporulation only the inner component of the wall gives rise to the wall of the spores; the outer component remains as a sac partially surrounding the mature spores, and is still covered by the fibrous layer.

The comparatively simple technique of carbon replicas (Bradley \& Williams, 1957), particularly when combined with freeze-drying, greatly increases the amount of structure observable on the surfaces of bacteria. In electron micrographs of carbon replicas of Streptomyces violaceoruber, details of the structure of the fibrous coat and its behaviour during sporulation are clearly seen. The nature of the surfaces of streptomycete spores as seen in electron micrographs (that is whether they are smooth or bear projections of various forms) has recently been used as a character for the classification of the group (see Tresner, Davies \& Backus, 1961, for references). Perhaps carbon replicas would enable differences to be detected amongst the many strains which have smooth spores, and might also reveal more clearly the structure of the spiny or hairy processes present in certain strains. It is probable that many of these processes are part of a superficial layer (Welch \& Lechevalier, 1960) comparable to the fibrous coat of $S$. violaceoruber, rather than projections of the spore wall proper. The significance of the superficial layer, whether it bears processes or not, is unknown; possibly it is responsible for the difficulty with which streptomycete spores are wetted by water, a property that may enable them to be dispersed on air-water interfaces in the upper layers of the soil, rather than sink to lower regions. No structures comparable to the fibrils of the coat of $S$. violaceoruber have been reported on the surfaces of other bacteria; the 'paired fibrous structure' found in lysed mycobacteria by Takeya, Mori, Koike \& Toda (1958) had dimensions very similar to those of the fibrils in $S$. violaceoruber, but this component was stated to be on the inside of the walls.

One of the authors (A.M.G.) is a Sir Halley Stewart Research Fellow. 


\section{REFERENCES}

Baldaccr, E. \& Grein, A. (1955). Esame della forma delle spore di attinomiceti al microscopio elettronico e loro valutazione ai fini di una classificazione. G. Microbiol. 1, 28.

Bradley, D. E. \& Williams, D. J. (1957). An electron microscope study of the spores of some species of the genus Bacillus using carbon replicas. J. gen. Microbiol. 17, 75 .

Brenner, S. \& Horne, R. W. (1959). A negative staining method for high resolution electron microscopy of viruses. Biochim. biophys. Acta, 34, 103.

Brieger, E. M., Cosslett, V. E. \& Glauert, A. M. (1954). Reproductive changes in avian tubercle bacilli studied with the electron microscope. J. gen. Microbiol. 10, 294.

Flaig, W., Beutelspacher, E., Küster, E. \& Segler-Holzweissig, G. (1952). Beitrag zur Physiologie und Morphologie der Streptomyceten. Plant \& Soil, 4, 118.

Glauert, A. M. \& Hopwood, D. A. (1959). A membranous component of the cytoplasm in Streptomyces coelicolor. J. biophys. biochem. Cytol. 6, 515.

Glauert, A. M. \& Hopwood, D. A. (1960). The fine structure of Streptomyces coelicolor. I. The cytoplasmic membrane system. J. biophys. biochem. Cytol. 7, 479 .

Glauert, A. M. \& Hopwood, D. A. (1961). The fine structure of Streptomyces violaceoruber (S. coelicolor). III. The walls of the mycelium and spores. J. biophys. biochem. Cytol. (in the Press).

Hopwood, D. A. (1960). Phase-contrast observations on Streptomyces coelicolor. J. gen. Microbiol. 22, 295.

Hopwood, D. A. \& Glauert, A. M. (1960). The fine structure of Streptomyces coelicolor. II. The nuclear material. J. biophys. biochem. Cytol. 8, 267.

Houwink, A. L. (1953). A macromolecular mono-layer in the cell wall of Spirillum spec. Biochim. biophys. Acta, 10, 360.

Houwink, A. L. (1956). Flagella, gas vacuoles and cell-wall structure in Halobacterium halobium; an electron microscope study. J. gen. Microbiol. 15, 146.

ITERSON, W. vaN (1954). Some thoughts on the possible relationship of bacterial flagella to cilia and flagella in other organisms. Proc. 3rd Int. Conf. on Electron Microscopy, p. 602.

LABAw, L. W. \& Mosley, V. M. (1954). Periodic structure in the flagella and cell walls of a bacterium. Biochim. biophys. Acta, 15, 325.

Mickle, H. (1948). Tissue disintegration. J. R. micr. Soc. 68, 10.

Salton, M. R. J. \& Williams, R. C. (1954). Electron microscopy of the cell walls of Bacillus megaterium and Rhodospirillum rubrum. Biochim. biophys. Acta, 14, 455.

TAkeYa, K., Mori, R., Kolke, M. \& Toda, T. (1958). Paired fibrous structure in mycobacteria. Biochim. biophys. Acta, 30, 197.

Tresner, H. D., Davies, M. C. \& Backus, E. J. (1961). Electron microscopy of Streptomyces spore morphology and its role in species differentiation. J. Bact. 81, 70.

Vernon, T. R. (1955). Spore formation in the genus Streptomyces. Nature, Lond. 176, 935.

Welch, M. M. \& Lechevalier, H. A. (1960). Ultramicroscopic structure of the spiny spore surface of Streptomyces violaceus No. 829. Bact. Proc. p. 54.

Note added in proof. In a recent paper J. Yamaguchi (Rep. Res. Inst. Tub. \& Leprosy, 9, 125, 1960) describes a similar fibrous layer which she considers to be on the outer surface of mycobacterial cell walls. 


\section{EXPLANATION OF PLATES}

The scale marks represent $0 \cdot 5 \mu$.

\section{Plate 1}

Figs. 1 to 4. Electron micrographs of intact spores of Streptomyces violaceoruber shadowed with gold/palladium.

Fig. 1. Freeze-dried spores with rough outlines. $\times 36,000$.

Fig. 2. Freeze-dried spores with smooth outlines. $\times \mathbf{3 6 , 0 0 0}$.

Fig. 3. Air-dried spores which are distorted. $\times 30,000$.

Fig. 4. The fibrous layer separated from the surface of a spore. $\times \mathbf{3 6 , 0 0 0}$.

Figs. 5 and 6. Electron micrographs of carbon replicas of freeze-dried hyphae of Streptomyces violaceoruber.

Fig. 5. Part of a hypha of the substrate mycelium with a structureless surface. $\times 66,000$.

Fig. 6. Part of a hypha of the aerial mycelium with an outer fibrous layer. Some of the fibrils appear beaded. $\times 66,000$.

\section{Plate 2}

Figs. 7 to 10. Electron micrographs of carbon replicas of freeze-dried spores of Streptomyces violaceoruber.

Fig. 7. The spores in a chain are covered with the fibrous layer. $\times 66,000$.

Fig. 8. The spores in a chain are surrounded by a loose sac derived from the parent hyphal wall. The spores and sac are covered with the fibrous layer. $\times 40,000$.

Fig. 9. The spores in a chain are beginning to separate from one another and the fibrous layer has broken between the spores, revealing the structureless spore wall (SW) underneath. $\times 30,000$.

Fig. 10. An isolated mature spore is closely surrounded by the fibrous layer. $\times 47,000$.

\section{Plate 3}

Figs. 11 to 13. Electron micrographs of carbon replicas of Streptomyces violaceoruber.

Fig. 11. Two freeze-dried spores are separating from one another and the fibrous layer has broken between them revealing the structureless spore wall (SW) underneath. $\times \mathbf{5 5 , 0 0 0}$.

Fig. 12. An air-dried spore which is distorted. $\times 35,000$.

Fig. 13. A spore has just started to germinate and the short germ tube has emerged through the fibrous layer; freeze-dried. $\times 41,000$.

\section{Plate 4}

Fig. 14. Electron micrograph of a carbon replica of Streptomyces violaceoruber. A group of spores has germinated and each has produced one or two germ tubes. The surfaces of the walls of the germ tubes show no structure, although the fibrous layer is still present on the spores. $\times 18,000$.

Fig. 15. Electron micrograph of a fragment of the wall of an aerial hypha of Streptomyces violaceoruber stained with potassium phosphotungstate. The hyphal wall has no visible structure. Part of the fibrous layer still covers one branch of the hypha. $\times 30,000$. 


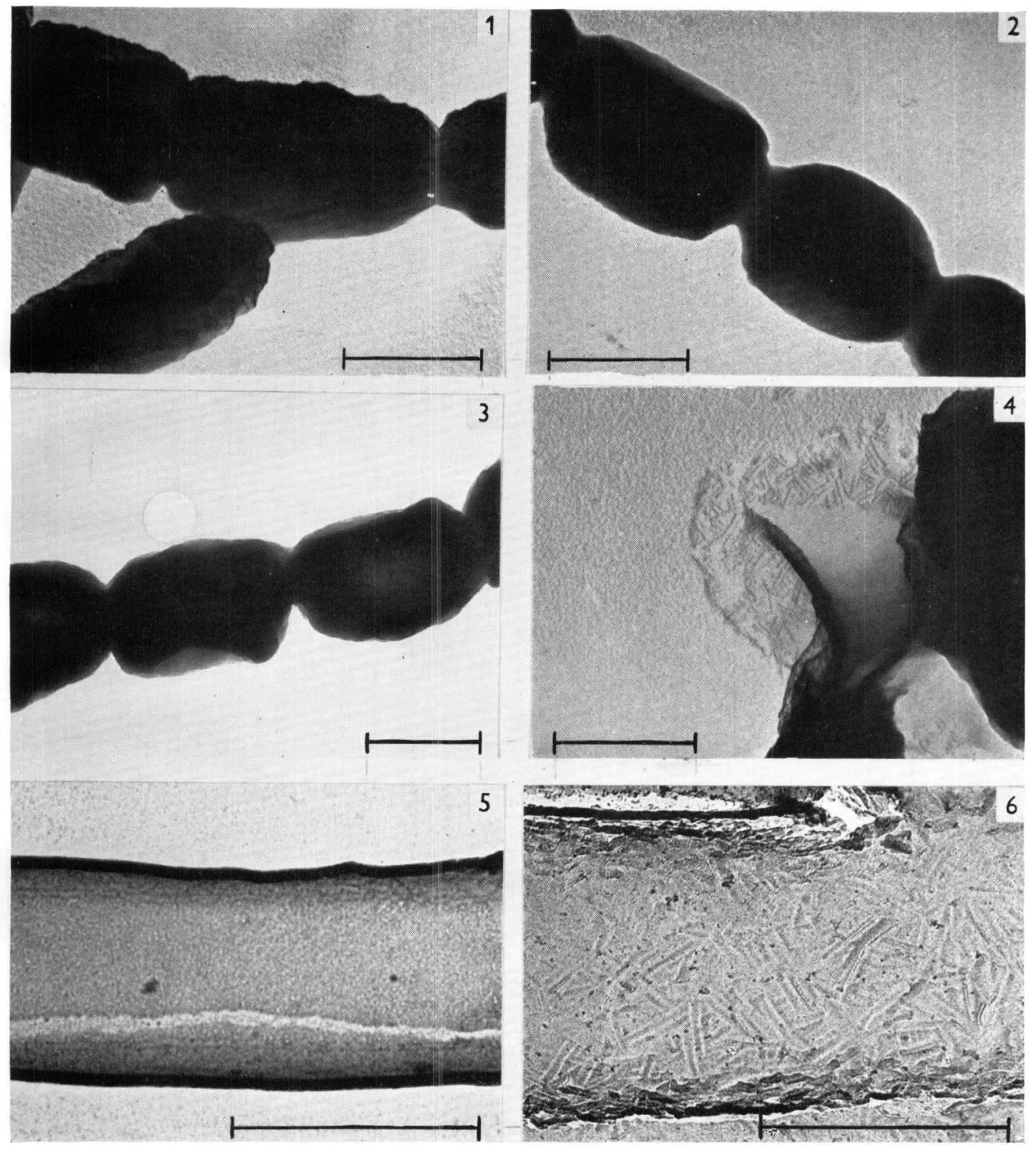


Journal of General Microbiology, Vol. 26, No. 2

Plate 2
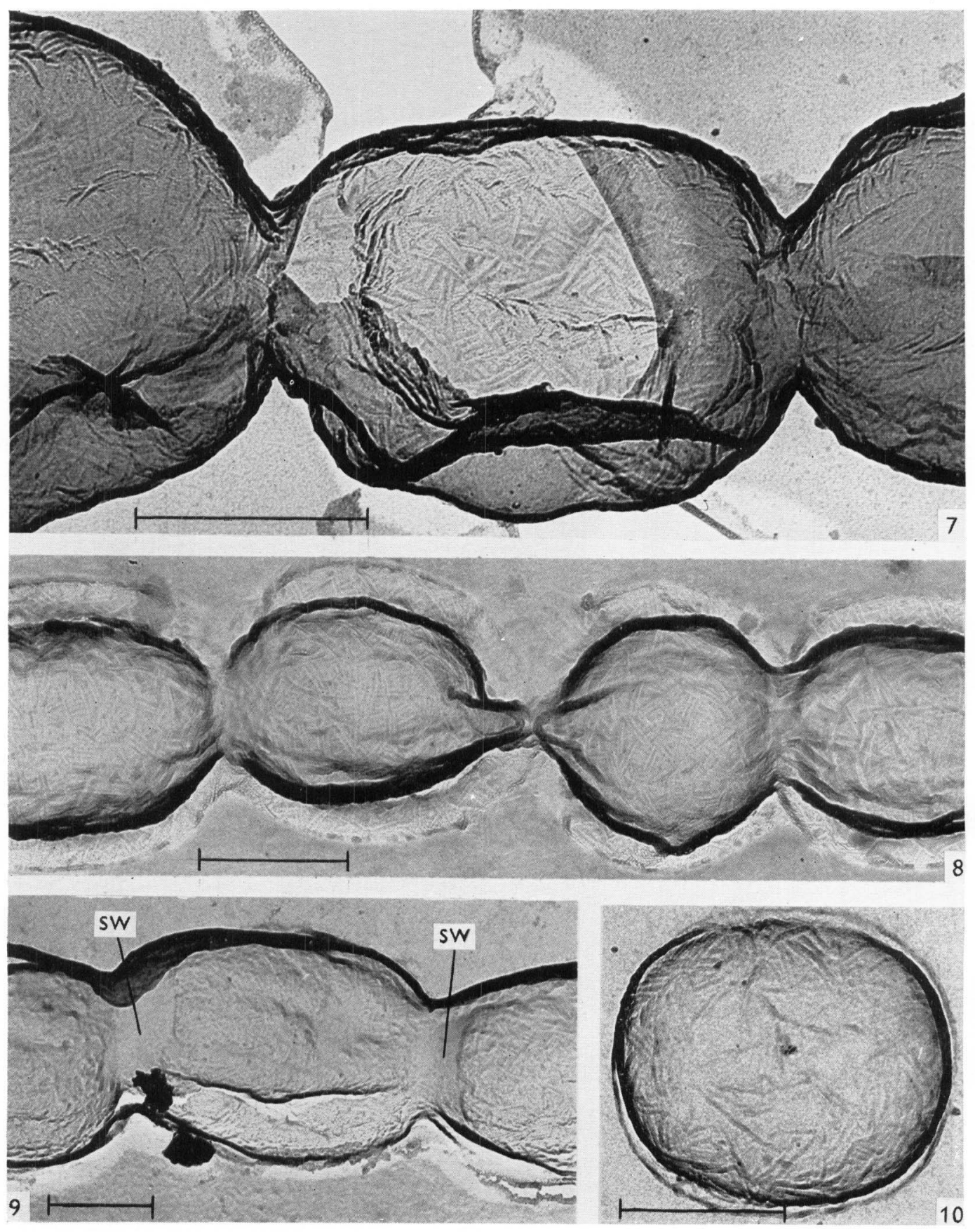

D. A. HOPIVOOD AND A. M. GLAUERT 
Journal of General Microbiology, Vol. 26, No. 2

Plate 3
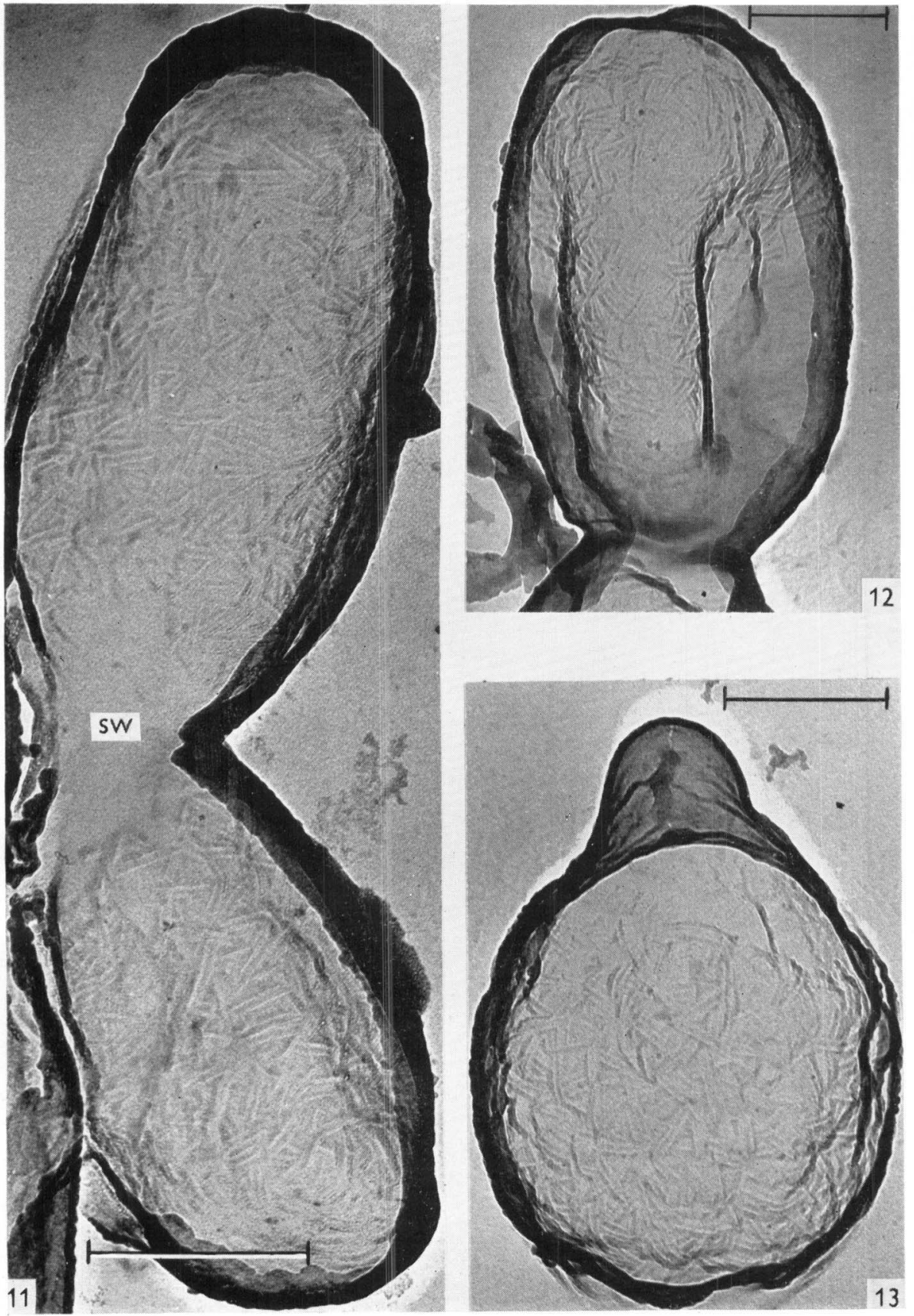

D. A. HOPWOOD ANI A. M. GLAUER'l 

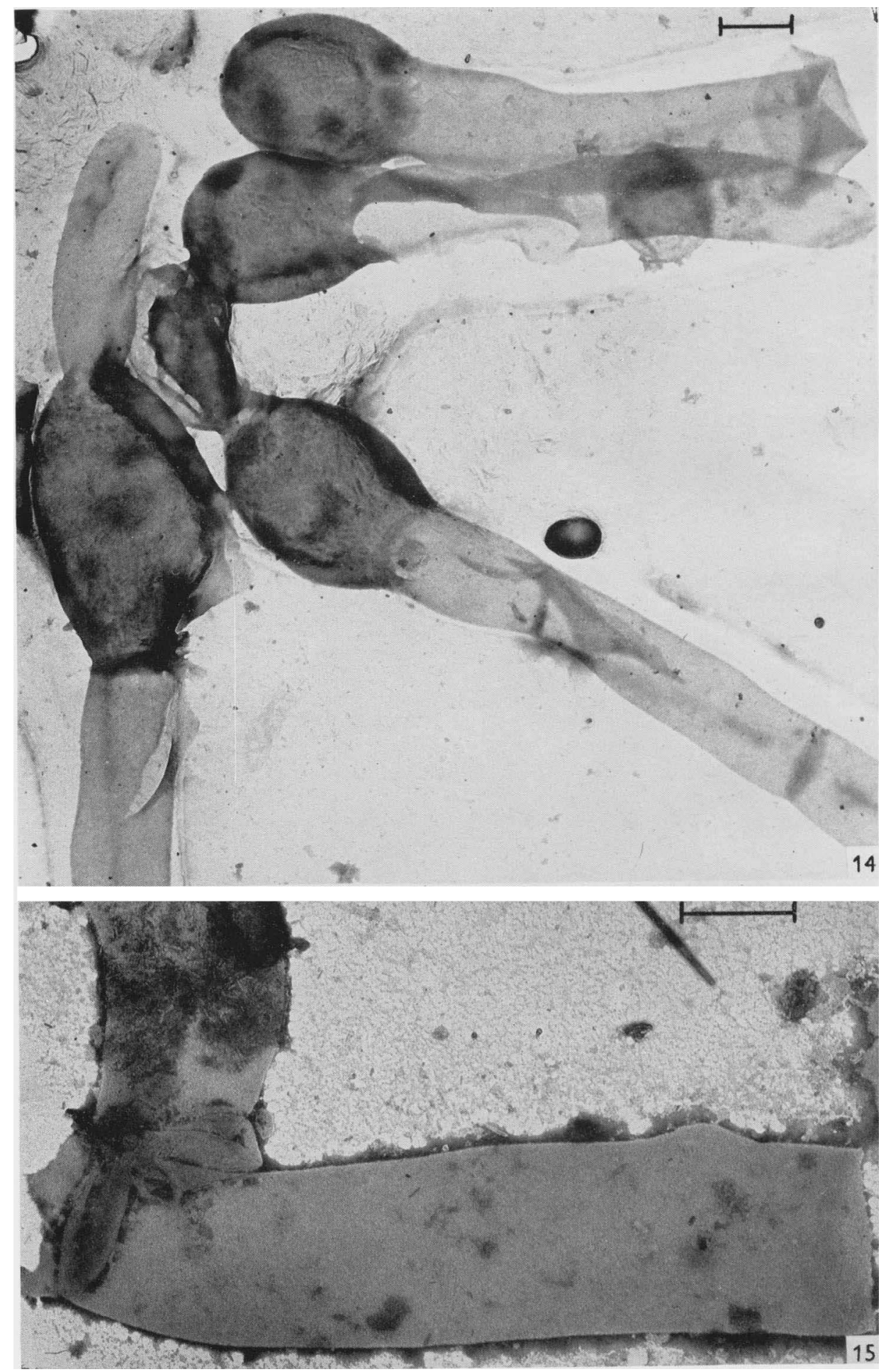

D. A. HOPWOOD AND A. M. GLAUERT 